\title{
Coexistence of Ankylosing Spondylitis and Multiple Sclerosis: Trigger with TNF-alpha Antagonist Therapy or Coincidental?
}

\author{
Ankilozan Spondilit ve Multipl Skleroz Birlikteliği: TNF-alfa Antagonist Tedavisi mi
} Tetikledi ya da Raslantisal mi?

Keywords: Ankylosing spondylitis, multiple sclerosis, TNF-alpha antagonist, adalimumab

Anahtar Kelimeler: Ankilozan spondilit, multipl skleroz, TNF-alfa antagonisti, adalimumab

\section{Dear Editor,}

Ankylosing spondylitis (AS) is a chronic systemic inflammatory rheumatic disease that affects the spine and the sacro-iliac joints. In the clinic, uveitis, psoriasis, and inflammatory bowel disease are the most frequent extra-articular manifestations. Neurologic complications are rare and seen as atlanto-axial dislocation, spinal fractures, spinal stenosis, and cauda equina syndrome (1).

The coexistence of AS and multiple sclerosis (MS) has been reported to be limited number. According to these case reports, although this coexistence may occur, demyelinating disease may develop following the use of tumor necrosis factor (TNF)-alpha antagonists for the treatment of AS.

A 27-year-old male patient, who had been diagnosed as having AS, was admitted to our neurology outpatient clinic due to numbness in the legs. His medical history included uveitis episodes in 2010 and 2011 (anterior and intermediate) and he was diagnosed as having AS in 2012 due to human leukocyte antigen (HLA)-B27 positivity, which was investigated for back and low back pain. Sulphasalazine was initiated. The patient was evaluated at another center due to headache in 2016; cranial magnetic resonance imaging (MRI) was performed (Figure 1) and the disorder was diagnosed as tension headache. In 2017, adalimumab was recommended instead of sulphasalazine. A neurologic examination of the patient, who had been using adalimumab for 5 months, was abnormal due to hyper-reflexia in the lower and upper extremities and left Babinski positivity. Cranial MRI with gadolinium $(\mathrm{Gd})$ revealed multiple hyper-intensities in the peri-ventricular and infratentorial white matter, corpus callosum, and pericallosal region on T2 images with and without Gd enhancement, a lesion in the centrum semi-ovale on T1 image, and cervical and thoracic MRI revealed T2 hyperintensities at $\mathrm{C} 2$, C3, C4, and T6, T7 without Gd (Figure 2).

Both P100 wave latencies were longer in visual evoked potential (R/P100:122.5 msec, L/P100:127.2 msec). Biochemistry, complete blood count, vitamin B12, folate, thyroid hormone, and auto-antibody test results were normal, hepatitis markers, ANA, anti-Ro, anti-La, Brucella, and anti-aquaporine- 4 antibody were negative. The oligoclonal band was positive in the cerebrospinal fluid (CSF). The patient was evaluated by a dermatologist because he had a history of aphthous lesions in the mucosa of the lip and the general examination result was normal. The pathergy test was negative. Ocular examination and fluorescence angiography were performed due to uveitis episodes and found to be normal. The patient was diagnosed as having MS. Adalimumab was discontinued by the rheumatologist and colchicine was commenced.

Coexistence of AS and MS is rare and its etiology has not yet been explained. A genetic predisposition is a hypothesis that has been proposed for the coexistence of AS and MS. Therefore, immunologic studies have been focused on HLA. It has been reported that only the HLA-B7 haplotype is commonly seen in both diseases and HLA-B7 and HLA-B27 show cross-reaction. The prevalence of HLA-B27 is similar to that seen in the normal population (2). Another reason for this hypothesis is that the cases reported in the literature demonstrate a certain geographic distribution. It was seen commonly in France, Greece, Italy, Spain,

\footnotetext{
Address for Correspondence/Yazışma Adresi: Bahar Say MD, Kırıkkale University Faculty of Medicine, Department of Neurology, Kirikkale, Turkey Phone: +903184444071 E-mail: drbaharsay@gmail.com ORCID: orcid.org/0000-0003-2595-3804

Received/Geliş Tarihi: 29.05.2018 Accepted/Kabul Tarihi: 10.04.2019

${ }^{\circ}$ Copyright 2019 by Turkish Neurological Society

Turkish Journal of Neurology published by Galenos Publishing House.
} 

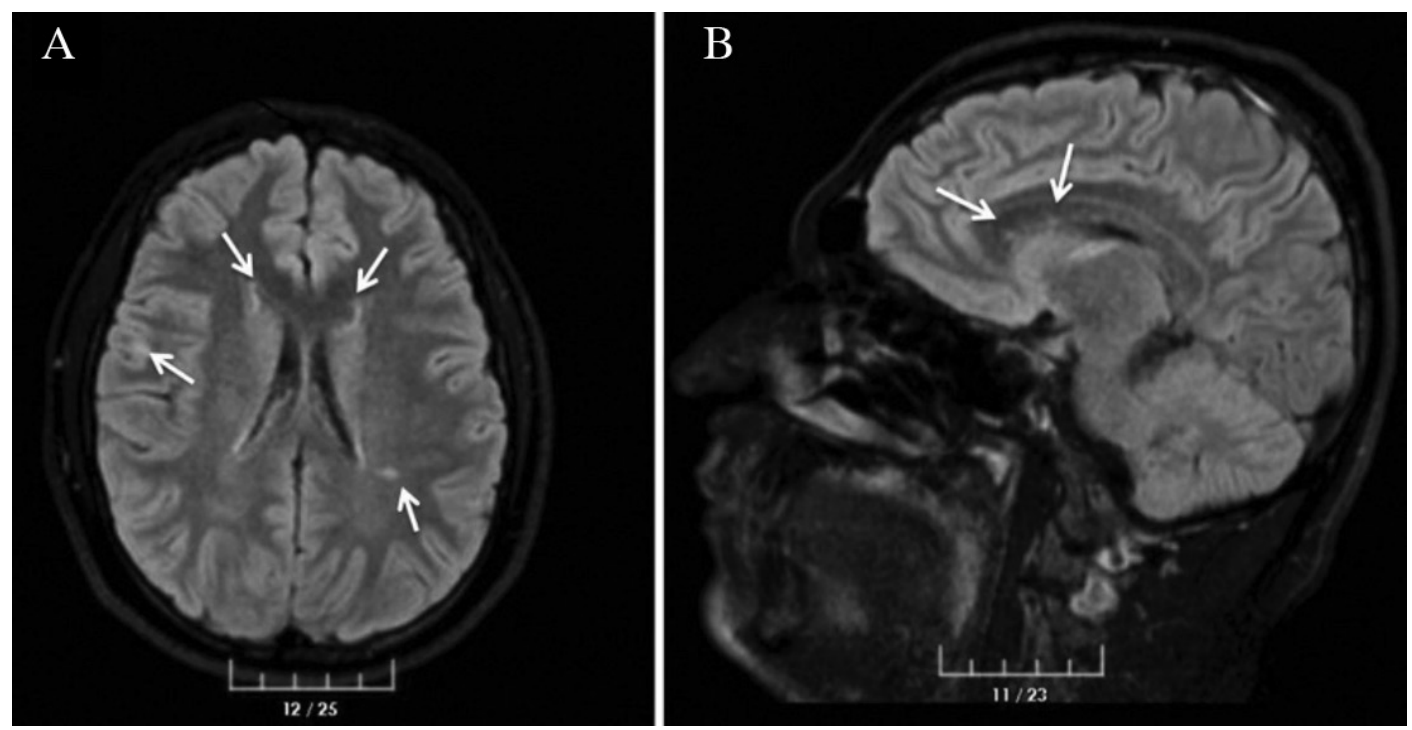

Figure 1. Cranial magnetic resonance imaging. A) Axial T2 periventricular and juxtacortical high signal intensity. B) Sagittal T2 corpus callosum punctate high signal intensity

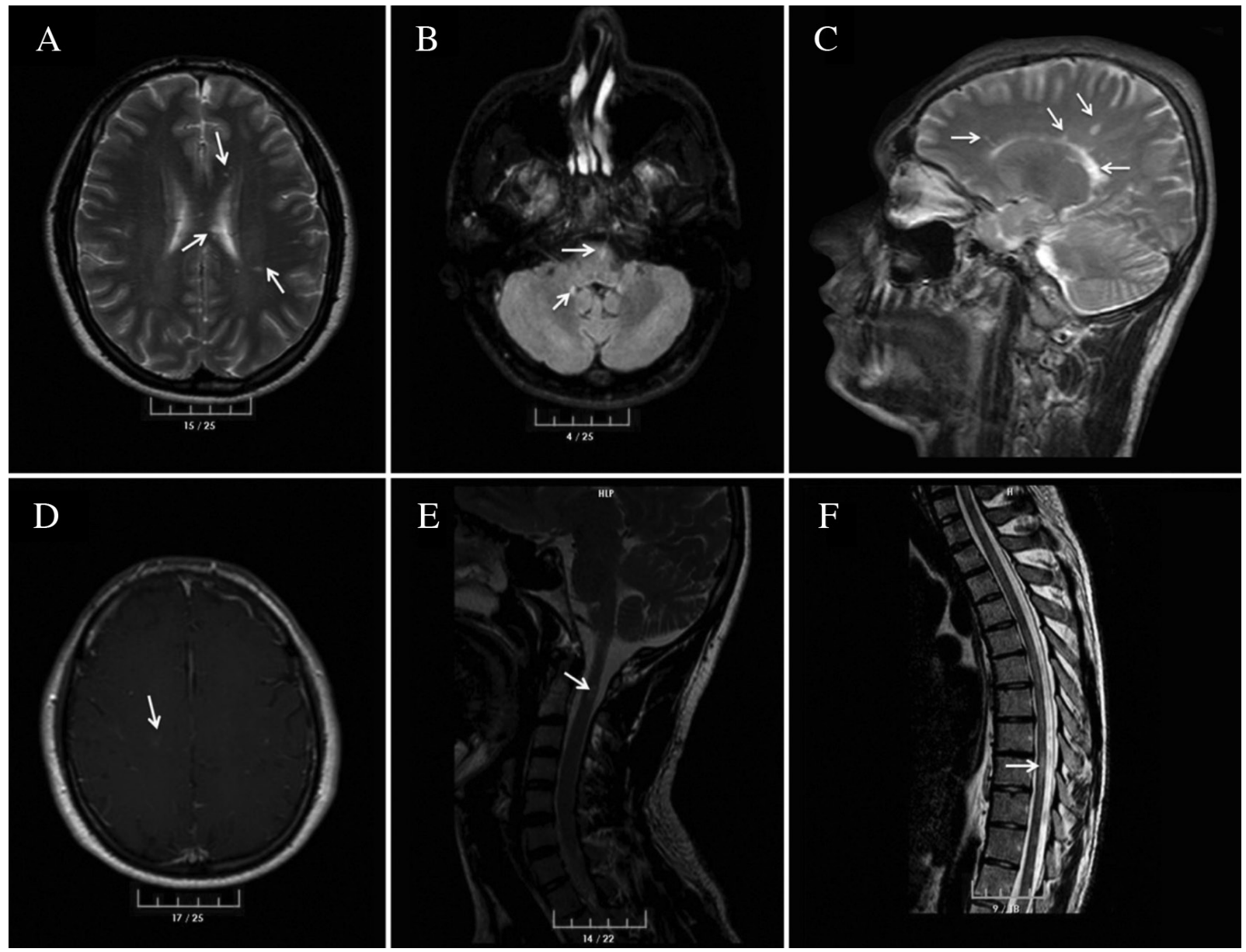

Figure 2. Cranial, cervical, thoracal magnetic resonance imaging. A) and B) Axial T2-weighted images show multiple foci of high signal intensity in the periventricular and infratentorial white matter C) Sagital T2, corpus callosum splenium and pericallosal ovoid high signal intensity D) Gd enhancement of a lesion in the centrum semiovale on Axial T1 E) Cervical T2-weighted C2, 3, and F) Thoracal T2 weighted Th 6, 7 signal intensity 
Germany, and Turkey, southern Europe, except for two cases reported from the United States of America. The number of the cases reported from Turkey is limited (3).

TNF-alpha antagonists used for the treatment of AS may be another factor responsible for the coexistence of AS and MS. Demyelinating lesions with TNF in the treatment of rheumatologic diseases have been reported. The etiology is still not known. There are several hypotheses including an increased entry of autoreactive $\mathrm{T}$ cells into the central nervous system, reduced TNF receptor 2 involvement in myelin repair, altered cytocine response, especially interleukin 10 and 12, and induced latent infection that might result in demyelinating lesions. The TNF-alpha antagonist adalimumab-related demyelination has rarely been reported (4). In our patient, MS may develop with the triggering of silent demyelinating lesions with adalimumab therapy.

Alternatively, intermediate uveitis may be a clue for the coincidental demyelinating disease in our patient. Anterior uveitis may be observed in spondylo-arthropathies such as AS and commonly coexists with HLA B27. Intermediate uveitis is usually associated with systemic diseases, but it was reported that MS could develop in $17 \%$ of patients with intermediate uveitis (5). Therefore, patients with intermediate uveitis are recommended to be evaluated and followed-up.

In conclusion, the coexistence of AS and MS may be occurred or new demyelinating pathology may occur with TNF-alpha antagonist therapy in AS. For this reason, cases should be evaluated in terms of the process of silent demyelinating process before TNF- alpha antagonist therapy and in the therapy phase, new lesions should be followed closely.

\section{Ethics}

Informed Consent: Consent form was filled out by all participants.

Peer-review: Externally peer-reviewed.

\section{Authorship Contributions}

Concept: U.E., Design: B.S., Data Collection or Processing: B.S., Analysis or Interpretation: B.S., U.E., Literature Search: B.S., U.E., Writing: B.S.

Conflict of Interest: No conflict of interest was declared by the authors.

Financial Disclosure: The authors declared that this study received no financial support.

\section{References}

1. El Maghraoui A. Extra-articular manifestations of ankylosing spondylitis: prevalence, characteristics and therapeutic implications. Eur J Intern Med 2011;22:554-560.

2. Borman P, Tuncay F, Köybaşi M, Ergun U, Inan L. Coexistence of ankylosing spondylitis and multiple sclerosis. Acta Neurol Belg 2011;111:340-343.

3. Fominykh V, Shevtsova T, Arzumanian N, Brylev L. Coexistence of multiple sclerosis and ankylosing spondylitis: Report of four cases from Russia and review of the literature. J Clin Neurosci 2017;44:230-233.

4. Kemanetzoglou E, Andreadou E. CNS Demyelination with TNF- $\alpha$ Blockers. Curr Neurol Neurosci Rep 2017;17:36.

5. Pan J, Kapur M, McCallum R. Noninfectious immune-mediated uveitis and ocular inflammation. Curr Allergy Asthma Rep 2014;14:409. 